\title{
Cancer Risk Assessment: Examining the Family Physician's Role
}

\author{
Carl V. Tyler, Jr., MD, MS, and Clint W. Snyder, PhD
}

Background: Cancer risk assessment begins in the primary care clinician's office. Essential components of that process include: 1) documentation of personal and family cancer information; 2) identification of families at increased risk for cancer; 3 ) modification of cancer screening recommendations according to degree of risk; 4) referral of high-risk individuals to cancer genetics clinics. The purpose of this study was to examine these 4 components of primary care cancer risk assessment using data abstracted from patient records at an academic family medicine center.

Methods: Ambulatory records of $\mathbf{7 3 4}$ patients were reviewed in their entirety for information relevant to cancer risk assessment. Detail of cancer information was categorized as comprehensive, adequate, or inadequate. Patient records were categorized as suggestive of average, moderate, or high genetic risk for cancer. For patients with a family history of colorectal cancer, modification of colon cancer screening to reflect degree of cancer risk was assessed. Finally, the frequency of cancer genetic referral in high-risk individuals was noted.

Results: The presence or absence of a family history of cancer was documented in $97.8 \%$ of records. There was insufficient information to adequately assess risk in $69.5 \%$ of charts. Detail of family cancer documentation was associated with personal history of cancer $(P=.001)$, patient age $(P=.001)$, and physician training status $(P=.042)$, but not with patient or physician gender, duration of care, or completion of a genogram. For persons with a family history of colorectal cancer, compliance with cancer screening individualized to degree of risk was achieved in $50 \%$ of patients. Ten patients met criteria for moderate or high genetic risk for cancer. None had been offered cancer genetics consultation.

Conclusions: Nearly all records documented the presence or absence of a family history of cancer. However, in those with a positive family history, the detail of information was insufficient to permit risk assessment in over two thirds of individuals; risk-stratified colon cancer screening was not achieved in half of the patients with a family history of colorectal cancer; individuals at moderate or high cancer risk were not identified as such; and those at high risk were not offered cancer genetics referral. In addition to collecting adequate family cancer information, family physicians need to adopt explicit risk assessment criteria to identify, and to optimally care for, those at increased genetic risk for cancer. (J Am Board Fam Med 2006;19:468-77.)

Family physicians play a pivotal role in cancer control by identifying those individuals whose behav-

This article was externally peer-reviewed.

Submitted 8 February 2006; revised 4 May 2006; accepted 25 May 2006.

From Fairview Hospital/Cleveland Clinic Family Medicine Residency Program, Department of Family Medicine, Case Western Reserve University School of Medicine, Cleveland, $\mathrm{OH}$ (CVT); and Northeastern Ohio Universities College of Medicine, Rootstown, OH (CWS).

Funding: This study was supported in part by the Department of Health and Human Services Academic Administrative Units in Primary Care Grant D54HP05447.

Conflict of interest: none declared.

Corresponding author: Carl V. Tyler, Jr., MD, MS, Geriatrics and Research Coordinator, Fairview Hospital/ Cleveland Clinic Family Medicine Residency Program, Associate Clinical Professor, Case Western Reserve University School of Medicine, Department of Family Medicine, 18200 Lorain Avenue, Cleveland, OH 44111 (E-mail: carl.tyler@fairviewhospital.org). ior, environment, and/or heredity place them at increased risk for developing cancer. For most individuals, a positive family history of cancer confers negligible or only slight additional risk. In a few, however, the family history suggests a genetic predisposition to cancer that requires modified screening strategies compared with the general population. Rarely, the family history is suggestive of a hereditary cancer syndrome that warrants referral to a cancer genetics specialist. With the promulgation of guidelines for management of persons at increased genetic risk for cancer, ${ }^{1}$ and the availability of genetic tests to identify those with hereditary cancer syndromes, ${ }^{2}$ family physicians play an increasingly crucial role in cancer risk assessment and management.

Although the recognition of genetic predisposition to cancer begins with an accurate family med- 
ical history, investigators have reported significant gaps in the documentation of family cancer history in primary care. Analyzing data from the Direct Observation of Primary Care study, Medalie et al found that just $40 \%$ of 2333 audited charts documented the presence or absence of a family history of breast or colon cancer. ${ }^{3}$ Similarly, in an audit of 500 charts from an academic family practice and 2 community family practices, Sifri et al found that the presence or absence of a family history of cancer was noted in only $56 \%$ of charts. ${ }^{4}$

Even when detailed family cancer history is obtained, how to interpret this information can be problematic. Uniformity in cancer risk assessment has been limited by variability of criteria utilized by different clinicians, institutions, and health insurance carriers. Moreover, risk assessment schemas have often focused on rarer, hereditary cancer syndromes while neglecting the more common dilemma (particularly for primary care clinicians) of distinguishing between average and moderate risk individuals. To facilitate more consistent and comprehensive risk assessment, Hampel et $\mathrm{al}^{5}$ conducted a comprehensive literature search, including a review of consensus statements from relevant professional societies, eg, the National Comprehensive Cancer Network. They devised a set of risk assessment criteria (see Table 1) that stratify family history into average, moderate, and high genetic risk. Individuals categorized as average risk should follow general population guidelines for cancer screening; moderate-risk persons require increased surveillance of at-risk organs, whereas high-risk groups require cancer genetics consultation as well as increased surveillance protocols.

The purpose of this research was to further explore how cancer risk assessment is conducted in a primary care setting. We examined how family cancer history is documented, particularly as it impacts the ability to stratify cancer risk. We examined whether certain patient and physician characteristics are associated with more detailed and informative cancer information. For individuals with a family history of colorectal cancer, we investigated whether screening recommendations were modified according to degree of risk. Finally, we examined whether individuals at high genetic risk for cancer had been identified as such and whether they had been referred for cancer genetics consultation.

\section{Methods}

This study was a retrospective audit of a random sample of charts obtained from an academic family medicine center. The entire medical record was reviewed for information related to personal and family history of cancer, including type of cancer, age at the time of diagnosis, gender, and relationship of family member to the index patient. Charts noting breast or ovarian cancer were further examined for inquiry regarding Ashkenazi Jewish ancestry and bilaterality of breast cancer. Charts noting melanoma were further scrutinized for documentation regarding multiple primary tumors.

Records indicating family histories of colorectal cancer were audited for colorectal cancer screening testing, including method, age at first screening, and frequency of screening. Patient age, gender, years of care at the center; gender and training status of the patient's primary physician; and completion of a genogram were recorded. Charts were carefully reviewed for any documentation to suggest that the primary physician suspected familial or hereditary cancer, and whether the patients were referred to a genetic counselor, geneticist, or oncologist because of a concern for familial or hereditary cancers.

Next, this cancer information was categorized as follows: "comprehensive" if the type of cancer, specific familial relationship, and age at diagnosis were all documented (eg, "breast cancer in maternal aunt in her 60s"); "adequate" if just the type of cancer and the familial relationship were documented (eg, "colon cancer in paternal uncle"); and "inadequate" if any less information was noted (eg, "positive family history of breast cancer.") Descriptive statistics were calculated for all variables. Relationships between patient or physician characteristics and adequacy of cancer information were assessed by $\chi^{2}$ statistics, with statistical significance set at $P=.05$.

Patient records documenting a family history of colorectal cancer were evaluated for adherence to risk-stratified colorectal cancer screening recommendations published by a consortium of gastroenterology societies. ${ }^{6}$

Cancer risk assessment criteria published by Hampel et $\mathrm{al}^{5}$ (see Table 1) were then applied to patients with a personal or family history of cancer and their risk was categorized as average, moderate, high, or unknown (due to insufficient information). 
Table 1. Risk Assessment Criteria ${ }^{5}$

\begin{tabular}{|c|c|}
\hline \multicolumn{2}{|l|}{ BREAST-OVARIAN } \\
\hline Non-Jewish families & Any of the following: \\
\hline \multirow[t]{7}{*}{ High-risk breast-ovarian } & 1 case of breast cancer $\leq 40$ years in an $\mathrm{FDR}^{*}$ or SDR \\
\hline & 1 FDR or SDR with both breast and ovarian cancer, at any age \\
\hline & $\geq 2$ cases of breast cancer in FDRs or SDRs if one is diagnosed at $\leq 50$ years or is bilateral \\
\hline & $\begin{array}{l}1 \text { FDR or SDR with breast cancer diagnosed at } \leq 50 \text { years or bilateral and } 1 \text { FDR or SDR with } \\
\text { ovarian cancer }\end{array}$ \\
\hline & 3 cases of breast and ovarian cancer (at least one case of ovarian cancer) in FDRs and SDRs \\
\hline & 2 cases of ovarian cancer in FDRs and SDRs \\
\hline & $\begin{array}{l}1 \text { case of male breast cancer in an FDR or SDR if another FDR or SDR has (male or female) } \\
\text { breast or ovarian cancer }\end{array}$ \\
\hline \multirow[t]{3}{*}{ Moderate-risk breast } & Any of the following: \\
\hline & 2 FDRs if both diagnosed between 51 and 60 years \\
\hline & $\begin{array}{l}1 \mathrm{FDR} \text { and SDR (mother or sister and maternal aunt or maternal grandmother), if sum of their } \\
\text { ages is } \leq 118 \text { years }\end{array}$ \\
\hline Moderate-risk ovarian & 1 FDR with ovarian cancer \\
\hline Jewish families & Any of the following: \\
\hline \multirow[t]{4}{*}{ High-risk breast-ovarian } & $\geq 1$ case of breast cancer $\leq 50$ years in an FDR or SDR \\
\hline & $\geq 1$ case of ovarian cancer at any age in an FDR or SDR \\
\hline & $\begin{array}{l}\geq 1 \text { FDR or SDR with breast cancer at any age if another FDR or SDR has breast and/or ovarian } \\
\text { cancer at any age }\end{array}$ \\
\hline & $\geq 1$ case of male breast cancer in an FDR or SDR \\
\hline \multicolumn{2}{|l|}{ COLON } \\
\hline \multirow[t]{4}{*}{ High-risk HNPCC } & Any of the following: \\
\hline & $\begin{array}{l}3 \text { FDRs or SDRs affected with any HNPCC-associated cancerst; all cases can occur in one } \\
\text { generation, no age restriction }\end{array}$ \\
\hline & 1 FDR or SDR with two or more HNPCC-associated cancers $\dagger$ \\
\hline & 1 FDR with $\mathrm{CRC}<50$ years \\
\hline \multirow[t]{2}{*}{ Moderate-risk colon } & 1 FDR with CRC $\geq 50$ years and one SDR with CRC at any age \\
\hline & 2 FDRs with $\mathrm{CRC} \geq 50$ at any age \\
\hline POLYPOSIS & Any FDR or SDR with $>10$ polyps \\
\hline \multicolumn{2}{|l|}{ PROSTATE } \\
\hline \multirow[t]{3}{*}{ High-risk prostate } & Any of the following: \\
\hline & 3 relatives affected, any age \\
\hline & 2 relatives affected (2 FDRs or $1 \mathrm{FDR}$ and $1 \mathrm{SDR}$ ), one diagnosed at $<60$ years \\
\hline \multirow[t]{4}{*}{ Moderate-risk prostate } & Any of the following: \\
\hline & 1 FDR diagnosed at $<60$ years \\
\hline & 2 FDRs with PC diagnosed at $>60$ years \\
\hline & $1 \mathrm{FDR}$ and one SDR with PC diagnosed at $>60$ years \\
\hline \multicolumn{2}{|l|}{ MELANOMA } \\
\hline High risk melanoma & $\begin{array}{l}3 \text { FDRs or SDRs affected with melanoma and or pancreatic cancer, at least } 2 \text { generations (must } \\
\text { include more than one case of melanoma) } \\
1 \text { FDR or SDR with multiple primary melanomas }\end{array}$ \\
\hline $\begin{array}{l}\text { Moderate-risk } \\
\text { melanoma }\end{array}$ & $\geq 1$ FDR with melanoma \\
\hline \multicolumn{2}{|c|}{ LI-FRAUMENI SYNDROME } \\
\hline \multirow[t]{6}{*}{ High-risk Li-Fraumeni } & All of the following: \\
\hline & 1 FDR or SDR with sarcoma, brain, or adrenal cancer diagnosed at $<45$ years; \\
\hline & And \\
\hline & 1 FDR or SDR with sarcoma, breast, brain, adrenal or leukemia at any age; \\
\hline & And \\
\hline & $1 \mathrm{FDR}$ or SDR with any cancer diagnosed at $<60$ years \\
\hline
\end{tabular}

(Table 1 continues) 
Table 1. Continued

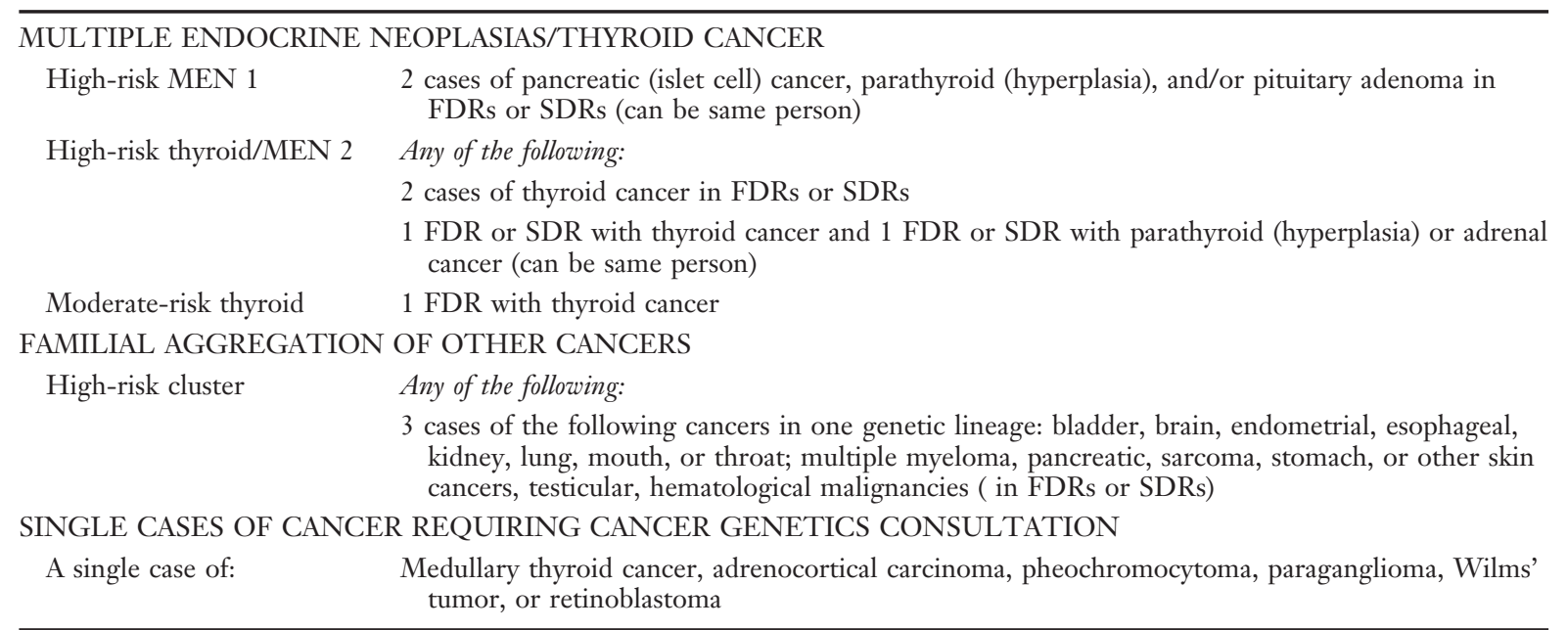

* FDR, first degree relative; CRC, colorectal cancer; HNPCC, hereditary non-polyposis colon cancer; MEN, multiple endocrine neoplasia; PC, prostate cancer; SDR, second degree relative.

† HNPCC-associated cancers. Colorectal, endometrial, stomach, ovary, small bowel, pancreas, ureter, or renal pelvis (as ureter and renal pelvis are too specialized to include on general screening questionnaire, 'kidney' can be accepted in lieu of these subtypes).

Finally, we examined whether patients categorized at moderate or high risk for cancer by Hampel criteria were recognized as such by their primary physician and whether they had been referred for cancer genetics consultation.

\section{Results}

A total of 734 charts were audited. The presence or absence of cancer in family members was documented in $97.8 \%$ of charts. A personal history of cancer was found in 21 charts, and a positive family history of cancer was noted in 271 charts.

According to the above categorization, the detail of family cancer information was considered comprehensive in $22(8.1 \%)$, adequate in $78(28.1 \%)$, and inadequate in 171 (63.1\%). Table 2 examines associations between patient or physician characteristics and the detail of family cancer history. Family cancer information was more detailed in older patients, those with a personal history of cancer, and those under the primary care of faculty physicians. A family history of colorectal cancer was documented in 25 charts. These were categorized into 4 familial risk categories, each linked to specific screening recommendations. The proportion of people in each category who received the recommended screenings is reported in Table 3. In 3 patients (12\%), there was insufficient information to allow risk stratification. Although tallied as "adherent" to the guidelines, 2 of the 4 patients with a single second-degree relative affected by colorectal cancer actually underwent screening earlier than necessary, as did one patient with a single firstdegree relative affected when over age 60 years. None of the (adult) patients with histories suggestive of hereditary non-polyposis colorectal cancer (HNPCC) had undergone any colorectal cancer screening at all.

Using cancer risk assessment criteria published by Hampel et al, ${ }^{5}$ applied to the 279 charts with a personal and/or family history of cancer, 75 (26.9\%) were considered average risk, 3 (1.1\%) were moderate risk, and 7 (2.5\%) were high risk. There was insufficient information to assess risk in $194(69.5 \%)$ of the charts. Of the 10 patients at moderate or high risk for cancer, only 3 had been identified in their medical record "at increased risk due to family cancer history." The cases at moderate or high genetic risk for cancer are further described in Table 4. None had been referred for cancer genetics consultation.

\section{Discussion}

Almost $98 \%$ of records documented the presence or absence of a family history of cancer, compared with rates of 40 to $68 \%$ cited in earlier studies. ${ }^{3,4}$ We suspect this high value is probably due to our practice utilization of a patient self-completed registration form that queries family history, including family cancer history. Our practice policy dictates 


\begin{tabular}{|c|c|c|c|c|}
\hline \multirow[b]{2}{*}{ Characteristic } & \multicolumn{3}{|c|}{ Family Cancer History $(\mathrm{N}=271)$} & \multirow[b]{2}{*}{$P$ Value } \\
\hline & Inadequate & Adequate & Comprehensive & \\
\hline \multicolumn{5}{|l|}{ Patient Gender } \\
\hline Female & $107(64.5 \%)$ & $43(25.9 \%)$ & $16(9.6 \%)$ & \multirow[t]{2}{*}{.275} \\
\hline Male & $64(61 \%)$ & $35(33.3 \%)$ & $6(5.7 \%)$ & \\
\hline \multicolumn{5}{|c|}{ Personal History of Cancer } \\
\hline Present & $6(50 \%)$ & $1(8.3 \%)$ & $5(41.7 \%)$ & \multirow[t]{2}{*}{.001} \\
\hline Absent & $165(63.7 \%)$ & $77(29.7 \%)$ & $17(6.6 \%)$ & \\
\hline \multicolumn{5}{|l|}{ Patient age } \\
\hline Pediatric (0 to 21$)$ & $56(86.2 \%)$ & $7(10.8 \%)$ & $2(3.1 \%)$ & \multirow{3}{*}{.001} \\
\hline Adult (22 to 65$)$ & $107(57.2 \%)$ & $62(33.2 \%)$ & $18(9.6 \%)$ & \\
\hline Geriatric $(>65)$ & $8(42.1 \%)$ & $9(47.4 \%)$ & $2(10.5 \%)$ & \\
\hline \multicolumn{5}{|l|}{ Duration of care } \\
\hline Less than 5 years & $72(63.2 \%)$ & $33(28.9 \%)$ & $9(7.9 \%)$ & \\
\hline Greater than 5 years & $99(63.1 \%)$ & $45(28.7 \%)$ & $13(8.3 \%)$ & .993 \\
\hline \multicolumn{5}{|l|}{ Genogram } \\
\hline Present & $10(52.6 \%)$ & $7(36.8 \%)$ & $2(10.5 \%)$ & \multirow[t]{2}{*}{.626} \\
\hline Absent & $160(63.7 \%)$ & $71(28.3 \%)$ & $20(8 \%)$ & \\
\hline \multicolumn{5}{|l|}{ Physician gender } \\
\hline Female & $62(71.3 \%)$ & $19(21.8 \%)$ & $6(6.9 \%)$ & \multirow[t]{2}{*}{.154} \\
\hline Male & $109(59.2 \%)$ & $59(32.1 \%)$ & $16(8.7 \%)$ & \\
\hline \multicolumn{5}{|l|}{ Physician status } \\
\hline Resident & $137(67.2 \%)$ & $51(25 \%)$ & $16(7.8 \%)$ & \\
\hline Faculty & $34(50.7 \%)$ & $7(40.3 \%)$ & $6(9 \%)$ & .042 \\
\hline
\end{tabular}

that the primary physician must review and sign that form before it may be filed in the chart.

Nearly $40 \%$ of charts indicated a positive family history of cancer. This value is congruent with the prevalence of a family history of cancer reported in large epidemiologic studies in the United States. ${ }^{7}$ What are still lacking, however, are the necessary detail and the interpretation of that information to allow accurate cancer risk stratification and appropriate intervention.

In our study, patient characteristics associated with more detailed family cancer histories included a personal history of cancer and greater age. It is not surprising that patients who have developed

Table 3. Colon Cancer Screening Recommendations for People With Familial Risk or Inherited Risk ${ }^{6}$

\begin{tabular}{|c|c|c|}
\hline Familial Risk Category & Screening Recommendation & $\begin{array}{l}\text { Proportion Adherent } \\
\text { to Screening } \\
\text { Recommendation }\end{array}$ \\
\hline $\begin{array}{l}\mathrm{FDR}^{*} \text { with } \mathrm{CRC} \text { or } \mathrm{AP} \text { at age } \geq 60 \text { years } \\
2 \text { SDRs with } \mathrm{CRC}\end{array}$ & Same as average risk but starting at age 40 years & $7 / 12(58 \%)$ \\
\hline $\begin{array}{l}2 \text { or more FDRs with CRC; FDR with CRC } \\
\text { or AP }<60 \text { years }\end{array}$ & $\begin{array}{l}\text { Colonoscopy every } 5 \text { years, beginning at } 40 \text { years } \\
\text { or } 10 \text { years younger than earliest diagnosis in the } \\
\text { family, whichever comes first }\end{array}$ & $0 / 3(0 \%)$ \\
\hline 1 SDR or any TDR with CRC & Same as average risk & $4 / 4(100 \%)$ \\
\hline Gene carrier or at risk for FAP & $\begin{array}{l}\text { Sigmoidoscopy annually, beginning age } 10 \text { to } 12 \\
\text { years }\end{array}$ & None \\
\hline Gene carrier of at risk for HNPCC & $\begin{array}{l}\text { Colonoscopy, every } 1 \text { to } 2 \text { years, beginning age } 20 \\
\text { to } 25 \text { years or } 10 \text { years younger than the earliest } \\
\text { case in the family, whichever comes first }\end{array}$ & $0 / 3(0 \%)$ \\
\hline
\end{tabular}

* FDR, first degree relative; CRC, colorectal cancer; AP, adenomatous polyp; SDR, second degree relative; TDR, third degree relative; FAP, familial adenomatous polyposis; HNPCC, hereditary nonpolyposis colorectal cancer. 
Table 4. Cases at Moderate or High Genetic Risk for Cancer*

\begin{tabular}{llll}
\hline Cancer Type & Genetic Risk & \multicolumn{1}{c}{ Criteria } & $\uparrow$ Risk Noted by PCP \\
\hline Breast-ovarian & High & Index patient with bilateral breast CA, onset $<40$ years & No \\
Breast-ovarian & High & SDR with both breast and ovarian CA & No \\
Breast & Moderate & 1 FDR and 1 SDR, sum of ages <118 years & Yes \\
Colon & High & 1 FDR with CRC <50 years and 1 FDR with CRC & No \\
& & and 1 SDR with CRC & No \\
Colon & High & SDR with CRC and SDR with endometrial CA and & Yes \\
Colon & High & SDR with ovarian CA & No \\
Colon & High & FDR with pancreatic CA and 2 SDRs with & Yes \\
Colon & Moderate & 2 FDRs with CRC & No \\
Prostate & Moderate & FDR $<60$ years & No \\
Melanoma & High & Index patient with multiple primary melanomas & \\
\hline
\end{tabular}

* As determined by Hampel et al criteria. ${ }^{5}$

† PCP, primary care physician; CA, cancer; FDR, first degree relative; SDR, second degree relative; CRC, colorectal cancer.

cancer themselves have probably sought more detailed medical history from family members and shared it with their family physician.

Although most cancer genetic risk manifests in adulthood, identification of families at increased genetic risk for cancer may be lifesaving even in childhood. For example, the rarer polyposis syndromes, such as familial adenomatous polyposis (FAP) and juvenile polyposis, manifest during late childhood and early adolescence, and risk reduction measures need to be instituted at that time. ${ }^{6}$ Other hereditary cancer syndromes manifesting as both adult- and childhood-onset cancers include LiFraumeni syndrome and multiple endocrine neoplasia type $2 .^{8}$ Moreover, in individuals with HNPCC, recommended cancer surveillance for both colonic and extra-colonic tumors should begin by age 20 to $25 .^{1}$

Patient gender, duration of care in the practice, and completion of a genogram were not associated with more detailed cancer histories. Because women are generally more knowledgeable about family health information, ${ }^{7}$ this suggests that what is recorded in the medical record fails to reflect everything that patients (particularly female patients) know. The incorporation of a genogram alone does not assure adequacy of family cancer history. Although the genetics literature frequently discusses the necessity of drawing a 3-generation pedigree in all patients, we need to ask whether the visualization of information in that form is necessary in primary care practice to recognize individuals at increased genetic risk for cancer. At present, only a minority of family physicians routinely utilizes genograms in clinical care. In the Direct Observation of Primary Care study, for example, only $13 \%$ of new patient charts included a genogram, compared with $11 \%$ of established patient charts. ${ }^{3}$ As more practices adopt electronic medical records, it is likely that even fewer primary care clinicians will routinely generate genograms, although computerized pedigree programs are commercially available. In addition, we need to examine clinical routines around updating, recording, and reassessing family history over time, because presently most family medical information is documented when the patient first establishes care with the family physician. ${ }^{9}$

Discussion in primary care regarding cancer genetics has sometimes focused on the relative rarity of specific hereditary cancer syndromes for which mutational testing is available, eg, BRCA1/ 2 or HNPCC. This emphasis neglects the far more common scenario whereby primary care physicians encounter patients whose family histories suggest an increased genetic risk for cancer, without meeting criteria for specific hereditary cancer mutations. These individuals may benefit from modified cancer screening protocols and other risk reduction measures.

For example, approximately $10 \%$ of adults bear a family history of colorectal cancer, whereas only $7 \%$ of colorectal cancer is due to high-risk genetic mutations such as those associated with HNPCC or FAP. The vast majority of genetic risk for colorectal cancer is related to one or more genes that 
confer modest risk, presumably interacting with environmental factors. ${ }^{1}$ The Multisociety Task Force on Colorectal Cancer Screening, ${ }^{6}$ the National Comprehensive Cancer Network (accessible at http://www.nccn.org), and others have crafted explicit screening guidelines for persons with a positive family history of colorectal cancer who do not meet criteria for high-risk hereditary cancer syndromes. Outcomes evidence for such enhanced cancer screening methodologies in moderate-risk patients is gradually accruing. A 16-year prospective study of these moderate-risk patients demonstrated an $80 \%$ reduction in the incidence of colorectal cancer by colonoscopic surveillance every 5 years. $^{10}$

Even when risk-stratified cancer screening protocols have been developed, both specialist and primary care clinician knowledge and implementation of these has been found lacking. ${ }^{11}$ In one study, gastroenterologists and primary care physicians were surveyed about their screening practices of individuals with moderate and high genetic risk for colorectal cancer. ${ }^{12}$ In all groups, overall compliance with recommended guidelines and notification of at-risk relatives was sub-optimal. Among the primary care physicians (PCPs) surveyed, 63\% routinely inquired about family history of colorectal cancer or adenomatous polyps; $55 \%$ recommended notification of at-risk first-degree relatives with family history of colorectal cancer; and 72\% appropriately chose age 40 to begin screening in a family with history of early-onset colorectal cancer. Only $57 \%$ of PCPs recommended genetic testing in persons at risk for HNPCC, and only 50\% recommended initiation of colorectal cancer screening in individuals with HNPCC at the age of 25. Even these rates of screening are probably overly generous, given studies that demonstrate physician self-report of cancer screening is typically inflated when compared with data from patient survey and chart audit sources. ${ }^{13}$ Nonetheless, in high-risk patients confirmed by genetic testing, adherence to cancer screening protocols has been strongly correlated with reinforcement by the primary care physician. ${ }^{14}$

On the other hand, patients, as well as clinicians, may overestimate cancer risk and initiate cancer screening prematurely or conduct screenings more frequently than is warranted. In our sample, one patient with a first-degree relative affected by colon cancer over age 60 underwent screening colonos- copy at age 37 , whereas another patient with a single affected second degree relative underwent screening flexible sigmoidoscopy at age 38 . Overperformance of screening endoscopy in patients with moderate risk of colorectal cancer consumes critical resources and interferes with achieving national goals for colorectal cancer screening. ${ }^{15}$ Similarly, there is evidence that surveillance colonoscopy is over-performed in individuals with low-risk lesions such as hyperplastic polyps and small adenomas. ${ }^{16}$ In Australia, supervised application of national best-practice guidelines significantly reduced the number of surveillance colonoscopies in persons with moderate risk of colorectal cancer. ${ }^{17}$

The risk assessment criteria developed by Hampel et $\mathrm{al}^{5}$ establishes a threshold for referring patients to cancer genetics clinics. Once a family history meets high-risk criteria, the family physician can refer the patient to a cancer genetics consultant, where further time-intensive inquiry into family history can be conducted, followed by analysis and individualized recommendations for cancer screening.

Limitations of this study include its single site family medicine residency training setting with its use of a paper medical record. An electronic medical record could afford many opportunities for improved history-taking and risk assessment, including prompted inquiry for specific information, a defined "location" for documenting family medical history to enhance gradual accumulation of information, and embedded risk assessment tools to assure up-to-date management and consultation for those individuals at increased risk.

We did not examine the effect of patient demographic variables such as race, education, or income on cancer risk assessment. In the United States, non-White populations are less likely to receive cancer screening ${ }^{18}$ and cancer genetics services. ${ }^{19}$ For example, analysis of the 2000 National Health Interview Survey revealed that Hispanics and persons with lower education levels were less likely to undergo colon cancer screening. The overall low prevalence of screening seemed to be related to lack of knowledge and to inadequate provider counseling rather than poor adherence to recommended screening. ${ }^{20}$ A case-control study of women with a family history of breast or ovarian cancer found that African American women were significantly less likely to undergo genetic counseling for BRCA1/2 testing than were White women; this 
disparity could not be explained by differences in risk factors for carrying a mutation, socioeconomic factors, risk perception, attitudes, or PCP recommendation. ${ }^{21}$

This study was also not designed to ascertain the source of inadequate family cancer history. A lack of patient knowledge, a failure to communicate known information during the patient encounter, and a failure to document shared information in the medical record all probably contributed to the outcome of inadequate documentation. Patients may intentionally withhold known genetic information because of fear that their health insurance rates will rise, they will lose their health insurance, or they will be unable to obtain it in the future if they change employers. ${ }^{22}$ Physicians may fail to ask the necessary detail required to stratify risk, eg, the age of diagnosis, primary tumor type, specific kinship, or ethnicity of affected relatives.

Although gaps in patient knowledge about their family cancer history surely contribute to the problem, it also seems likely that at least some information known to the patient is not incorporated into the medical record. Using touch screen computer kiosks in a comprehensive cancer center, over 4000 individuals reported their family cancer histories over the course of 3 years. Only $11.8 \%$ provided insufficient information for risk assessment, compared with the $69.5 \%$ rate found in our study. ${ }^{5}$ Providers can encourage patients to complete Web-based family history tools, such as "My Family Health Portrait" developed as part of the US Surgeon General's Family History Initiative, and bring their documents to office encounters (accessible at http://www.hhs.gov/familyhistory).

Our finding that faculty physicians, overall, documented more comprehensive histories than resident physicians suggests that eliciting and documenting family history is a skill that can be learned. In addition, family physicians in practice recognize the need for greater competency in this area. In a survey of Massachusetts Academy of Family Physicians members, $86 \%$ of respondents stated that screening for inherited cancer risk was important to their practices, but only $61.6 \%$ felt confident in their ability to do so. ${ }^{23}$ The American Academy of Family Physicians website has a number of excellent on-line resources to incorporate advances in cancer genetics into primary care. These include on-line video CME programs from the 2005 Annual Clinical Focus series "Genomics"; a self-ad-
Table 5. On-line Cancer Genetics Resources for Primary Care Clinicians

Genetics and Your Practice

www.marchofdimes.com/gyponline/index.bm2

Genetics in Clinical Practice: A Team Approach

Iml.Dartmouth.edu/education/cme/Genetics

Genetics in Primary Care

http://genes-r-us.uthscsa.edu/resources/genetics/primary_care.htm

Information for Genetics Professionals

www.kumc.edu/gec/geneinfo.html

National Human Genome Research Institute

www.genome.gov

ministered "Family Disease Checklist" for patients, and links to other Web sites. Table 5 lists additional resources for provider education and tools for clinical care.

Because this study was not a direct observation of care, additional study limitations include the possibility that physician recommendations for cancer genetics referral occurred but were undocumented. However, given the medical liability for failure to warn a patient about cancer risk, ${ }^{24}$ if the physician recognized the patient to be at such high risk as to advise referral to a cancer genetics clinic, it seems unlikely that such discussions would occur completely unrecorded.

Admittedly, meticulous compilation and analysis of family cancer information are the first steps in a highly individualized, complex referral process. When a dismal 7 (1.9\%) of 362 patients at high risk for hereditary or early-onset cancer responded to a written invitation for cancer genetic counseling, Sweet et $\mathrm{al}^{25}$ conducted focus groups to better understand the cancer risk communication process. Focus group participants preferred the term "cancer risk assessment" over "genetic counseling"; an immediate, personalized risk message, with graphics as well as text; and a variety of options to choose from in managing that risk.

The poor uptake of genetic testing by individuals even at high genetic risk for cancer is one example of the highly complex and yet incompletely understood psychosocial dimensions of cancer risk assessment. Most individuals with a family history suggestive of low or moderate risk overestimate their personal cancer risk. ${ }^{26}$ Among 200 first-degree relatives of breast cancer patients who were at low to moderate risk of cancer, less than $10 \%$ of women reported subjective risk estimates within 10 
percentage points of their actual risk; only $2 \%$ underestimated their risk. ${ }^{27}$ Intention to undergo genetic testing is more strongly correlated with perceived rather than actual risk for cancer. In persons at low risk, genetic counseling may not diminish their personal perceptions of cancer risk or dissuade them from genetic testing. ${ }^{26}$

Families exert important and powerful influences on cancer risk assessment decisions and processes. Initial estimation of cancer risk is predicated on accurate and timely sharing of medical information between family members. In persons already affected by cancer, a frequently cited motivation for genetic testing is the desire to "help family members make health-related decisions." 28 Families also mediate the emotional impact of test results. Individuals who test positive for a cancer-associated mutation may feel less encouraged to express their emotions within the family, ${ }^{29}$ whereas individuals who test negative may experience "survivor guilt." At all levels of cancer risk, families influence adherence to cancer screening and surveillance recommendations. ${ }^{30}$

Communication of individualized risk estimates will probably translate into improved participation in cancer surveillance programs for individuals at moderate risk. A Cochrane systematic review of randomized controlled trials (mostly involving cancer screening programs) found that providing patients with an individualized risk estimate, as opposed to receiving general information about risks and benefits, increases the probability that they will participate in screening programs. ${ }^{31}$

Studies of cancer chemoprevention agents exemplified by STAR (study of tamoxifen and raloxifene) and SELECT (selenium and vitamin E cancer prevention trial) offer the hope of expanding opportunities for cancer prevention. ${ }^{32}$ At the same time, researchers are examining how best to modify cancer screening and management of persons at increased risk. We need to assure that our primary care systems adequately identify and accurately stratify individuals at increased risk for cancer, as well as keep pace with advancements in their care.

We acknowledge Silpa Kilaru, Luis Santiago, and Rachel Van Gilder for their assistance in data collection. We thank Kathryn Gaughan for assistance in the preparation of this manuscript.

\section{References}

1. Eberl MM, Sunga AY, Farrell CD, Mahoney MC. Patients with a family history of cancer: identification and management. J Am Board Fam Pract 2005; 18:211-7.

2. Sifri R, Gangadharappa S, Acheson L. Identifying and testing for hereditary susceptibility to common cancers. CA Cancer J Clin 2004;54:309-26.

3. Medalie JH, Zyzanski SJ, Langa D, Stange KC. The family in family practice: is it a reality? J Fam Pract 1998;46:390-6.

4. Sifri RA, Wender R, Paynter N. Cancer risk assessment from family history: gaps in primary care practice. J Fam Pract 2002;51:856.

5. Hampel H, Sweet K, Westman JA, Offit K, Eng C. Referral for cancer genetics consultation: a review and compilation of risk assessment criteria. J Med Genet 2004;41:81-91.

6. Winawer S, Fletcher R, Rex D, et al. Colorectal cancer screening and surveillance: clinical guidelines and rationale- update based on new evidence. Gastroenterology 2003;124:544-60.

7. Pinsky PF, Kramer BS, Reding D, Buys S. Reported family history of cancer in the prostate, lung, colorectal, and ovarian cancer screening trial. Am J Epidemiol 2003;157:792-9.

8. Strahm B, Malkin D. Hereditary cancer predisposition in children: genetic basis and clinical implications. Int J Cancer 2006; Epub ahead of print: April 26.

9. Acheson LS, Wiesner GL, Zyzanski S, Goodwin MA, Stange KS. Family history-taking in community practice: implications for genetic screening. Genet Med 2000;2:180-5.

10. Dove-Edwin I, Sasieni P, Adams J, Thomas J. Prevention of colorectal cancer by colonoscopic surveillance in individuals with a family history of colorectal cancer: 16 year prospective, follow-up study. BMJ 2005;331:1047. Epub 2005 Oct 21.

11. Gennarelli M, Jandorf L, Cromwell C, Valdimarsdottir H, Redd W, Iskaowitz S. Barriers to colorectal cancer screening: inadequate knowledge by physicians. Mt Sinai J Med 2005;72:36-44.

12. Schrony PC, Barriron AF, Ling BS, Wilson S, Geller AC. Family history and colorectal cancer screening: a survey of physician knowledge and practice patterns. Am J Gastroenterol 2002;97:1031-6.

13. Montano DE, Phillips WR. Cancer screening by primary care physicians: a comparison of rates obtained from physician self-report, patient survey, and chart audit. Am J Public Health 1995;85:795-800.

14. Tinley ST, Houfek J, Watson P, et al. Screening adherence in BRCA1/2 families is associated with primary physicians' behavior. Am J Med Genet A 2004;125:5-11.

15. Brown ML, Klabunde CN, Mysliwiec P. Current capacity for endoscopic colorectal cancer screening 
in the United States: data from the National Cancer Institute Survey of Colorectal Cancer Screening Practices. Am J Med 2003;115:129-33.

16. Mysliwiec PA, Brown ML, Klabunde CN, Ransohoff DF. Are physicians doing too much colonoscopy? A national survey of colorectal surveillance after polypectomy. Ann Intern Med 2004;141:264-71.

17. Bampton PA, Sandford JJ, Young GP. Applying evidence-based guidelines improves use of colonoscopy resources in patients with a moderate risk of colorectal neoplasia. Med J Aust 2002;176:155-7.

18. Paskett ED, Tatum C, Rushing J, et al. Racial differences in knowledge, attitudes, and cancer screening practices among a triracial rural population. Cancer 2004;101:2650-9.

19. Hall M, Olopade O. Confronting genetic testing disparities: knowledge is power. JAMA 2005;293: 1783-5.

20. Wee CC, McCarthy EP, Phillips RS. Factors associated with colon cancer screening: the role of patient factors and physician counseling. Prev Med 2005;41:23-9.

21. Armstrong K, Micco E, Carney A, Stopfer J, Putt M. Racial differences in the use of BRCA1/2 testing among women with a family history of breast or ovarian cancer. JAMA 2005;293:1729-36.

22. Clayton EW. Ethical, legal, and social implications of genomic medicine. N Engl J Med 2003; 349:562-9.

23. Gramling R, Nash J, Siren K, Eaten C, Culpepper L. Family physician self-efficacy with screening for inherited cancer risk. Ann Fam Med 2004;2:130-2.
24. Severin MJ. Genetic susceptibility for specific cancers: medical liability of the clinician. Cancer 1999; 86:1744-9.

25. Sweet K, Willis SK, Ashida S, Westman JA. Use of fear-appeal techniques in the design of tailored cancer risk communication messages: implications for healthcare providers. J Clin Oncol 2003;21:3375-6.

26. Croyle RT, Lerman C. Risk communication in genetic testing for cancer susceptibility. J Natl Cancer Inst 1999;25:59-66.

27. Gail MH, Brinton LA, Byar DP, et al. Projecting individualized probabilities of developing breast cancer for white females who are being examined annually. J Natl Cancer Inst 1989;23:22-30.

28. Kinney AY, DeVellis BM, Skrzynia C, Millikan R. Genetic testing for colorectal carcinoma susceptibility. Cancer 2001;91:57-65.

29. McInerney-Leo A, Biesecker BB, Hadley DW, et al. BRCA1/2 testing in hereditary breast and ovarian cancer families. II: Impact on relationships. Am J Med Genet A 2005;133:165-9.

30. Madlensky L, Esplen MJ, Gallinger S, et al. Relatives of colorectal cancer patients: factors associated with screening behavior. Am J Prev Med 2003;25:187-94.

31. Edwards A, Unigwe S, Elwyn G, Hood K. Effects of communicating individual risks in screening programmes: Cochrane systematic review. BMJ 2003; 327:703-9.

32. Tsao AS, Kim ES, Hong WK. Chemoprevention of cancer. CA Cancer J Clin 2004;54:150-80. 